\title{
Structural diversity in serine derived homochiral metal organic frameworks
}

\author{
TANAY KUNDU* and RAHUL BANERJEE* \\ Physical/Materials Chemistry Division, National Chemical Laboratory, Dr. Homi Bhabha Road, \\ Pune 411 008, India \\ e-mail: t.kundu@ncl.res.in; r.banerjee@ncl.res.in
}

MS received 30 July 2014; revised 29 August 2014; accepted 1 September 2014

\begin{abstract}
Two new $\mathrm{Zn}$ (II) and Cd(II) based homochiral metal-organic frameworks (MOFs) [SerCdOAc and $\mathrm{Zn}(\mathrm{Ser})_{2}$ ] have been synthesized using pyridyl functionalized amino acid, viz., serine, as an organic linker. The SerCdOAc structure is three dimensional, while that of the $\mathrm{Zn}(\mathrm{Ser})_{2}$ is two dimensional. The polar voids of the corresponding MOFs are filled with solvent molecules (water in the case of SerCdOAc and methanol in the case of $\left.\mathrm{Zn}(\mathrm{Ser})_{2}\right)$. In both cases, metal centres, i.e., $\mathrm{Zn}(\mathrm{II})$ and $\mathrm{Cd}(\mathrm{II})$, are hexacoordinated. However, with a change in the solvent for synthesis, ligand coordination mode and incorporation of additional coordinated anion resulted in a great change in the final MOF architecture. Herein, for the first time, we could achieve structural variety and synthesize MOFs composed of only metal ion and pyridyl functionalized amino acid linker.
\end{abstract}

Keywords. Amino acid; crystal engineering; hydrogen bonding; metal organic framework.

\section{Introduction}

Enantiopure amino acids and their derivatives have been a cynosure in the eyes of researchers as they serve as a backbone to the chemical processes of all flora and fauna. Extensive research on the property studies of the naturally occurring amino acids and their derivatives (e.g., peptides) as well as their synthetic analogues has been done over the last few decades for their biomimetic activities. ${ }^{1}$ Yet, complete understanding of their structure and property relationships seem extremely complicated till date. For example, a small change in an amino acid within the peptide backbone results in an unexpected twist in the peptide conformers. Hence, comprehensive understanding of the basic interactions between amino acids and other analytes would reveal the key features of the amino acid functional properties, and ultimately serve as the basis to comprehend various chemical processes in vivo. In this respect, several attempts have been made in order to introduce amino acid moiety in organic polymers for high $\mathrm{CO}_{2}$ affinity. On the other hand, organic-inorganic hybrid structures based on amino acids find their applications in enantioselective catalysis, ${ }^{2}$ separation, ${ }^{3}$ and most importantly to understand complex biochemical processes and cycles. ${ }^{4}$ In this respect, metal-organic frameworks (MOFs) serve as a boon for application

\footnotetext{
*For correspondence
}

in chiral separation and sensing, and nonlinear optics. MOFs are organic-inorganic hybrid porous material with potential applications like gas sorption, ${ }^{5}$ catalysis, ${ }^{6}$ magnetism, ${ }^{7}$ and conductivity. ${ }^{8}$ Hence, introduction of amino acid moiety in extended three dimensional backbone of MOF promises unique functionality and applicability owing to different side-arm residues of amino acids. Nevertheless, high binding and chelation ability of pure amino acids with transition metals often usher in zero/one dimensional complex formation instead of higher order porous MOFs. ${ }^{9}$ Not surprisingly, three dimensional MOFs with amino acid backbone are only a handful in number till date. ${ }^{10}$

Recently, our research group has attempted to use amino acid derived links (pyridyl functionalized valine, alanine, threonine, leusine, serine, etc.) to overcome the aforementioned problem. ${ }^{11}$ We have rationally tuned these amino acid derived links in MOF backbone to afford extended homochiral MOFs with interesting topologies along with microporosity, which serve as porous platforms to understand the structure and property relationships. ${ }^{11 \text { a }}$ These MOFs are water stable and undergo hydrolysis-mediated recrystallization at higher temperatures $\left(>90^{\circ} \mathrm{C}\right)$. The coordinated anions play a vital role in their differential recrystallizion performances. Moreover, minute change in the constituting anion (from $\mathrm{Cl}^{-}$to $\mathrm{Br}^{-}, \mathrm{HCO}_{2}^{-}$and $\mathrm{CH}_{3} \mathrm{CO}_{2}^{-}$) manifests in a decrease in water sorption capability and proton conducting ability. ${ }^{11 \mathrm{~d}}$ However, effect of a systematic change of the metal ion in amino acid-derived MOFs 
and the impact on structural integrity as well as property of the voids are still in infancy.

Herein, we report two new $\mathrm{Zn}(\mathrm{II})$ and $\mathrm{Cd}(\mathrm{II})$ based homochiral MOFs, i.e., CdSerOAc and $\mathrm{Zn}(\mathrm{Ser})_{2}$. These MOFs have been synthesized using a pyridylfunctionalized amino acid, viz., serine, as an organic linker. The CdSerOAc MOF structure is three dimensional, having polar voids filled with solvent water molecules (three water molecules per asymmetric unit in case of SerCdOAc). The water molecules are hydrogen bonded to both MOF backbone as well as to themselves. These water molecules adopt complex hydrogen bonded helical chains running through the tetragonal polar voids of the SerCdOAc. However, in the case of $\mathrm{Zn}(\mathrm{Ser})_{2}$, the resulting MOF adopts two dimensional sheet like structure, and the triangular voids are filled with solvent methanol molecules hydrogen bonded with the framework as well as the uncoordinated $-\mathrm{CH}_{2} \mathrm{OH}$ groups protruding into the pore. In both cases, the metal centres [ $\mathrm{Zn}(\mathrm{II})$ and $\mathrm{Cd}(\mathrm{II})]$ are hexacoordinated. However, with a change in the solvent for synthesis, ligand coordination mode and incorporation of additional coordinated anion resulted in dimensionality difference of the final MOF architecture. In this manuscript, for the first time, we could achieve structural variety as well as synthesize MOFs composed of only metal and pyridyl functionalized amino acid linker.

\section{Experimental}

\subsection{Materials and methods}

All reagents were commercially available and used as received. Powder x-ray diffraction (PXRD) patterns were recorded on a Phillips PANalytical diffractometer for $\mathrm{Cu} \mathrm{K}_{\alpha}$ radiation $(\lambda=1.5406 \AA)$ with a scan speed of $2^{\circ} \mathrm{min}^{-1}$ and a step size of $0.02^{\circ}$ in $2 \theta$. Fourier transform infrared (FT-IR) spectra were taken on a Bruker Optics ALPHA-E spectrometer with a universal Zn-Se ATR (attenuated total reflection) accessory in the 600 $4000 \mathrm{~cm}^{-1}$ region or using a Diamond ATR (Golden Gate). Thermo-gravimetric analyses (TGA) were carried out on a TG50 analyzer (Mettler-Toledo) or a SDT Q600 TG-DTA analyzer under $\mathrm{N}_{2}$ atmosphere at a heating rate of $10^{\circ} \mathrm{C} \mathrm{min}{ }^{-1}$ within a temperature range of $20-900^{\circ} \mathrm{C}$.

\subsection{General data collection and refinement procedures}

All single crystal data were collected on a Bruker SMART APEX ${ }^{12 a}$ three circle diffractometer equipped with a CCD area detector and operated at $1500 \mathrm{~W}$ power $(50 \mathrm{kV}, 30 \mathrm{~mA})$ to generate $\mathrm{Mo} \mathrm{K} \alpha$ radiation $(\lambda=0.71073 \AA)$. The incident $\mathrm{x}$-ray beam was focused and monochromated using Bruker Excalibur Gobel mirror optics. All crystals reported in this paper were mounted on nylon CryoLoops (Hampton Research) with Paraton-N (Hampton Research).

Initial scans of each crystal were performed to obtain preliminary unit cell parameters and to determine the mosaicity (breadth of spots between frames) of the crystal to select the required frame width for data collection. In every case frame widths of $0.5^{\circ}$ were judged to be appropriate and full hemispheres of data were collected using the Bruker SMART software suite. Following data collection, reflections were sampled from all regions of the Ewald sphere to re-determine unit cell parameters for data integration and to check for rotational twinning using CELL_NOW. ${ }^{12 \mathrm{c}}$ Fortunately, no crystal decay was encountered during data collection. Following exhaustive review of the collected frames, the resolution of the dataset was judged. Data were integrated using Bruker SAINT Software ${ }^{12 b}$ with a narrow frame algorithm and a 0.400 fractional lower limit of average intensity. Data were subsequently corrected for absorption by the program SADABS. The space group determinations and tests for merohedral twinning were carried out using XPREP. In all cases, the highest possible space group was chosen.

All structures were solved by direct methods and refined using the SHELXTL 97 software suite. ${ }^{12 \mathrm{~d}}$ Atoms were located from iterative examination of difference F-maps following least squares refinements of the earlier models. Final models were refined anisotropically (if the number of data permitted) until full convergence was achieved. Hydrogen atoms were placed in calculated positions $(\mathrm{C}-\mathrm{H}=0.93 \AA$ ) and included as riding atoms with isotropic displacement parameters 1.2-1.5 times $U_{\text {eq }}$ of the attached $\mathrm{C}$ atoms. All structures were examined through the Adsym subroutine of PLATON ${ }^{12 \mathrm{e}}$ to ensure that no additional symmetry could be applied to the models. All ellipsoids in ORTEP diagrams are displayed at the 50\% probability level unless stated otherwise. Crystallographic parameters are listed in tables 1 and 2.

\subsection{Synthesis}

2.3a (pPyridin-4-ylmethyl)-L-serine.NaOAc [SerOAc]: To an aqueous solution $(10 \mathrm{~mL})$ of L-serine $(1.9 \mathrm{~g}$, $17 \mathrm{mmol})$ and $\mathrm{Na}_{2} \mathrm{CO}_{3}(0.91 \mathrm{~g}, 8.5 \mathrm{mmol})$, 4-pyridinecarboxaldehyde $(1.82 \mathrm{~g}, 17 \mathrm{mmol})$ in $\mathrm{MeOH}(10 \mathrm{~mL})$ was added slowly under vigorous stirring. The solution was stirred for $1 \mathrm{~h}$ and cooled to $0-5^{\circ} \mathrm{C}$ in an ice bath. 
$\mathrm{NaBH}_{4}(0.76 \mathrm{~g}, 20.4 \mathrm{mmol})$ in $5 \mathrm{~mL}$ of $\mathrm{H}_{2} \mathrm{O}$ was slowly added. The mixture was then stirred for another $3 \mathrm{~h}$, and the $\mathrm{pH}$ was adjusted to $5-6$ using $3 \mathrm{~N} \mathrm{AcOH}$. The clear solution was stirred further for $2 \mathrm{~h}$ and then evaporated to dryness. The solid was extracted in hot and dry $\mathrm{MeOH}(150 \mathrm{~mL} \times 3)$, and the filtrate was evaporated in a rotavapor to get the ligand as a sodium acetate salt in the form of a white powder. Yield: $2.6 \mathrm{~g}, 60 \%$. Figure $7 \mathrm{~b}$ displays the IR spectrum.

$2.3 \mathrm{~b} \quad\left[\{\mathrm{Cd}(\mathrm{Ser})(\mathrm{OAc})\}\left(\mathrm{H}_{2} \mathrm{O}\right)_{3}\right]_{\infty}[\mathrm{SerCdOAc}]:$ To an aqueous solution $(1 \mathrm{~mL})$ of SerOAc $(0.05 \mathrm{~g}, 0.2 \mathrm{mmol})$, $\mathrm{Cd}\left(\mathrm{CH}_{3} \mathrm{COO}\right)_{2} \cdot 2 \mathrm{H}_{2} \mathrm{O}(0.022 \mathrm{~g}, 0.1 \mathrm{mmol})$ in $5 \mathrm{~mL}$ $\mathrm{MeOH}$ was added and sonicated for $10 \mathrm{~min}$ to produce a clear solution, which was left for evaporation for 48 $72 \mathrm{~h}$ to produce rod-shaped transparent crystals. Yield: $0.025 \mathrm{~g}, 65 \%$. Elemental analysis: calcd C (31.40\%), $\mathrm{H}(4.79 \%), \mathrm{N}(6.66 \%)$; found C (31.20\%), H (4.18\%), $\mathrm{N}(6.55 \%)$. Figure $7 \mathrm{~b}$ displays the IR spectrum. CCDC No. 1021364.

$2.3 \mathrm{c} \quad\left[\left\{\mathrm{Zn}(\mathrm{Ser})_{2}\right\}\left(\mathrm{CH}_{3} \mathrm{OH}\right)\right]_{\infty}\left[\mathrm{Zn}(\mathrm{Ser})_{2}\right]:$ To a methanolic solution $(5 \mathrm{~mL})$ of SerOAc $(0.05 \mathrm{~g}, 0.2 \mathrm{mmol})$, $\mathrm{Zn}\left(\mathrm{CH}_{3} \mathrm{COO}\right)_{2} 2 \mathrm{H}_{2} \mathrm{O} \quad(0.022 \mathrm{~g}, 0.1 \mathrm{mmol})$ in $5 \mathrm{~mL}$ $\mathrm{MeOH}$ was added and sonicated for $10 \mathrm{~min}$ to produce a clear solution. The solution was left for evaporation for $24-48 \mathrm{~h}$ to produce rod-shaped transparent crystals. Yield: $0.025 \mathrm{~g}, 65 \%$. Elemental analysis: calcd C (46.20\%), H (5.81\%), N (10.77\%); found C (45.82\%), $\mathrm{H}(5.58 \%), \mathrm{N}(10.65 \%)$. Figure $7 \mathrm{~d}$ displays the IR spectrum. CCDC No. 1021363.

\section{Results and Discussion}

Among all the 20 amino acids variants, serine serves as an important proteogenic amino acid with an extra hydroxymethyl functional group apart from the amino and the carboxy moieties. As a result, serine based materials possesses further opportunity for functionalization at the sidearm. Numerous synthetic methodologies have been developed for functionalized serine based biopolymers and soft materials. However, serine derived organic-inorganic hybrid materials are few in number. Nonetheless, a handful of them have utility in functional applications. For example, pyridyl functionalized serine linker has been utilized to prepare $\mathrm{Cu}$ based coordination polymer, which was used as a solid state catalyst for Biginelli catalytic reaction of benzaldehyde, urea and ethyl acetoacetate. ${ }^{13}$ However, the resulting framework is one dimensional. 1D materials suffer from the problem of unwanted leaching, poor structural ordering and lower thermal stability than higher dimensional materials. As a result, higher dimensional serine based materials with empty void inside the structure can be envisaged as a suitable solution for the current problems. In this regard, our group has developed a pyridyl serine based porous MOF using $\mathrm{Cd}(\mathrm{II})$ as metal node. Moreover, the $\mathrm{SerCdCl} \mathrm{MOF}^{11 \mathrm{~b}}$ possesses 3D architecture with tetragonal polar voids and coordinated chlorine atoms as well as coordinated hydroxymethyl groups apart from the imino and carboxylate moieties, which exposed towards the pore aperture. The polar atoms are responsible for the highly hydrophilic nature of the resulting structure. The Ser$\mathrm{CdCl} \mathrm{MOF}$ exhibited high hydroplilicity and can selectively adsorb water molecules over nitrogen and hydrogen molecules. These findings open up a new avenue for the systematic exploration of the serine derived linker as an efficient platform to create functional porous MOFs. In this work, we have further synthesized two new MOFs based on the same linker but with two different metal ions [ $\mathrm{Zn}(\mathrm{II})$ and $\mathrm{Cd}(\mathrm{II})]$ and they exhibit structural as well as property difference based on their constituents discussed vide supra.

\subsection{Crystal structure of SerCdOAc}

SerCdOAc crystallizes in the $P 2_{1} 2_{1} 2_{1}$ space group, comprising one $\mathrm{Cd}(\mathrm{II})$, one Ser ligand, one $\mathrm{OAc}^{-}$ion and three lattice $\mathrm{H}_{2} \mathrm{O}$ molecules in the asymmetric unit (figure 2a). The $\mathrm{Cd}(\mathrm{II})$ centre adopts a slightly distorted square bipyramidal geometry, chelated by bidentate carboxylate $[(\mathrm{Cd} 1-\mathrm{O} 1 ; 2.504(2) \AA)$ and $(\mathrm{Cd} 1-\mathrm{O} 2$; $2.274(2) \AA)]$, one amino functionality $[(\mathrm{Cd} 1-\mathrm{N} 2$; 2.331(1) $\AA)]$ and one pyridyl functionality $[(\mathrm{Cd} 1-\mathrm{N} 1$; 2.329(2) $\AA$ )] of the Ser linker coordinate to the axial and equatorial positions of the $\mathrm{Cd}(\mathrm{II})$, respectively (figures 1 and 2). Interestingly, the hydroxymethyl $\left(-\mathrm{CH}_{2} \mathrm{OH}\right)$ group of the Ser linker coordinates with $\mathrm{Cd}(\mathrm{II})$ without losing its proton, which implies neutral binding mode of the same. One $\mathrm{OAc}^{-}$ion coordinates to the equatorial site in a bidentate fashion [(Cd1-O4; 2.481(2) $\AA$ ) and (Cd1-O5; 2.322(2) $\mathrm{A})]$, which balances the overall negative charge of the $\mathrm{Cd}(\mathrm{II})$ atom. All adjacent $\mathrm{Cd}(\mathrm{II})$ nodes are connected by the pyridyl and carboxylate functionality to form a helical pitch along the crystallographic $a$-axis. The pyridyl moieties constitute tetragonal pore wall of the framework, which is hydrophobic in nature. The open channels along crystallographic $a$-axis are filled with solvent $\mathrm{H}_{2} \mathrm{O}$ molecules, which are three in number per asymmetric unit of SerCdOAc (figure 3a). The water molecules are strongly hydrogen bonded by nearby carboxylate oxygen atoms $[(\mathrm{O} 2 \ldots \mathrm{O} 7 ; 2.939(2) \AA$ and $\mathrm{O} 2 \cdots \mathrm{H} 7 ; 2.107(5) \AA)]^{14}$ and the coordinated acetate 


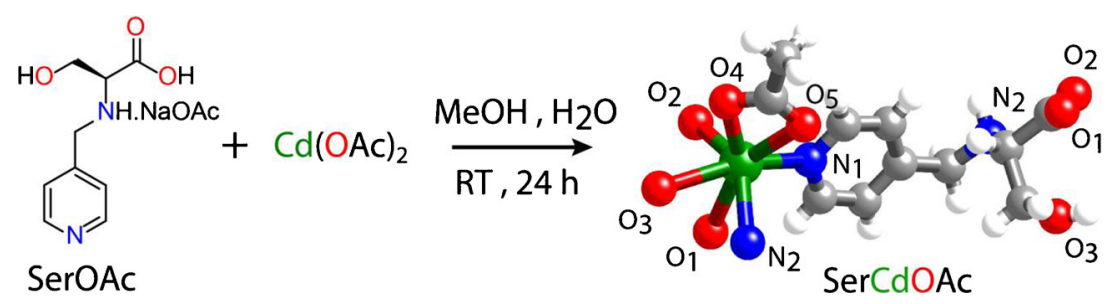

Figure 1. Schematic synthesis of the SerCdOAc MOF from the SerOAc ligand and $\mathrm{CdOAc}_{2}$ in the water medium. The coordination environment along the $\mathrm{Cd}$ atom is depicted in the right hand side with atom numbering. Colour codes: Cd (dark green), N (blue), O (red), C (gray) and H (white).

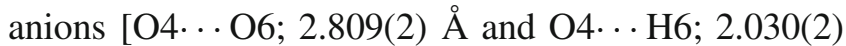
$\AA ̊$ )] due to high hydrophilic intermolecular interactions between the coordinated hydroxymethyl $\left(-\mathrm{CH}_{2} \mathrm{OH}\right)$ groups, carboxylate moieties and the $\mathrm{Cd}(\mathrm{II})$-bound acetate anions (exposed towards the pore) with the water molecules (figure $3 \mathrm{~b}$ ). These channels have a cylindrical cross sectional area of $8.5 \times 5.4 \AA$. A striking feature observed in this case is the hydrophilic interaction between ligand sidearm (i.e., coordinated hydroxymethyl $\left(-\mathrm{CH}_{2} \mathrm{OH}\right)$ groups) and carboxylate moieties [O3 . . O10, 3.321(7) $\AA$ ], which is one of its kind in the field of amino acid based MOFs. There are further intermolecular $\mathrm{O}-\mathrm{H} \cdots \mathrm{O}$ hydrogen bonds along the pore as well as between the neighbouring $\mathrm{H}_{2} \mathrm{O}$ molecules due to short separation (ca. 2.7-2.8 $)$ ). The homochiral framework constitutes a helical arrangement along crystallographic $a$ axis. The water molecules are hydrogen bonded (figure 3c) with the carboxylate moieties of the linker and the coordinated acetate anions of the MOF that are exposed towards the pore cavity.

Comparing the molecular structure of the MOF viz., SerCdOAc with earlier structure of the same type of constituent $(\mathrm{SerCdCl})$ resulted in a huge difference, although both belong to the 3D category. The SerCdCl consists of pentacoordinated distorted square pyramidal Cd centre; while SerCdOAc has hexacoordinated slightly distorted square bipyramidal geometry. This is possible due to the bidentate mode of the acetate ion in SerCdOAc, while monodentate chloride anion coordinates to the $\mathrm{Cd}$ centre in $\mathrm{SerCdCl}$. The increase in coordination number resulted in enhanced hydroplilicity of SerCdOAc over the $\mathrm{CdserCl}$, which is evident from the increased number of water molecules per unit despite slight decrease in the pore size of the former. This aforementioned observation hints at future design of water adsorbent materials, where optimization of polar interactions should be the prime criteria over the pore size.

\subsection{Crystal structure of $\mathrm{Zn}(\mathrm{Ser})_{2}$}

$\mathrm{Zn}(\mathrm{Ser})_{2}$ crystallizes in the $C 2$ space group, comprising one $\mathrm{Zn}(\mathrm{II})$, two Ser ligands and one lattice
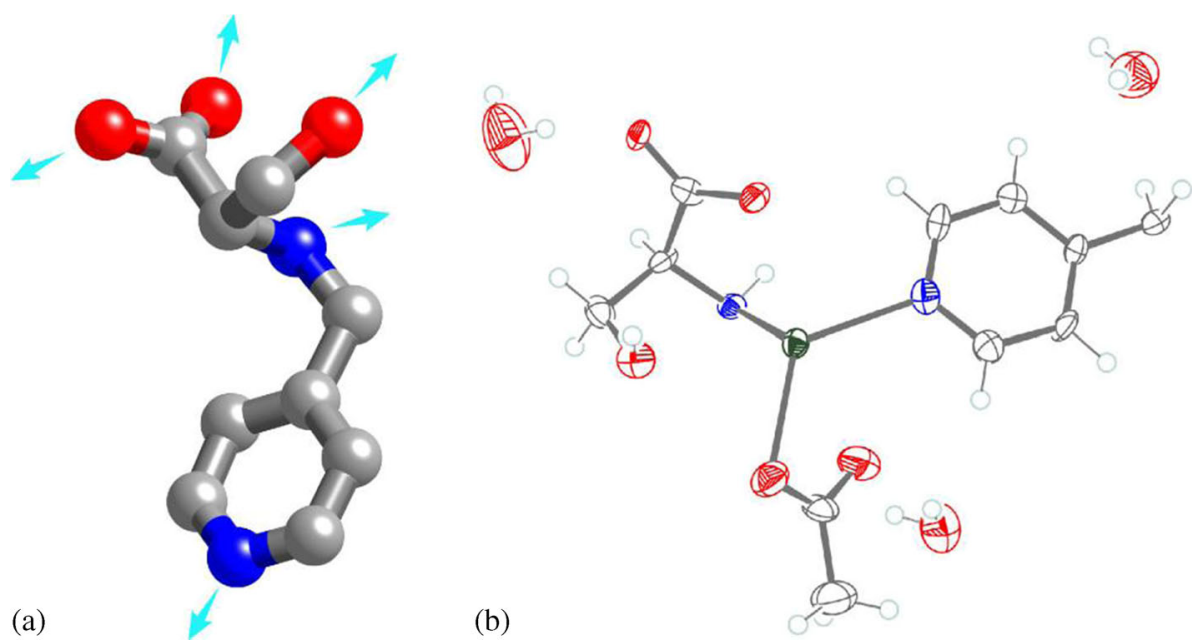

Figure 2. (a) Coordination mode of the Ser ligand utilized for the MOF formation. (b) ORTEP diagram of SerCdOAc MOF with all the atoms at 50\% probability level. 


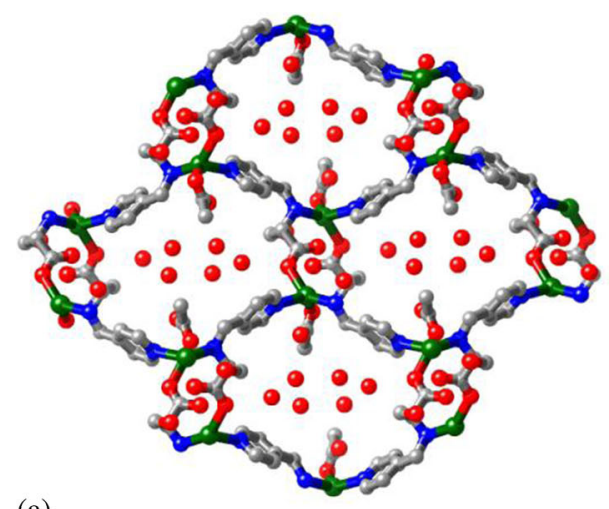

(a)

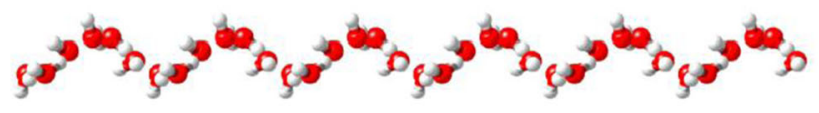

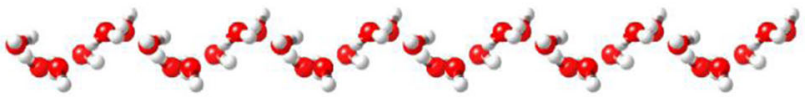

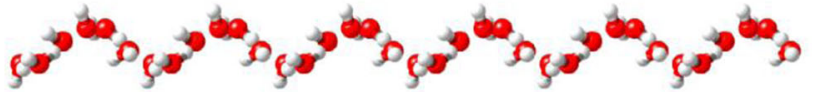

(c)

(b)
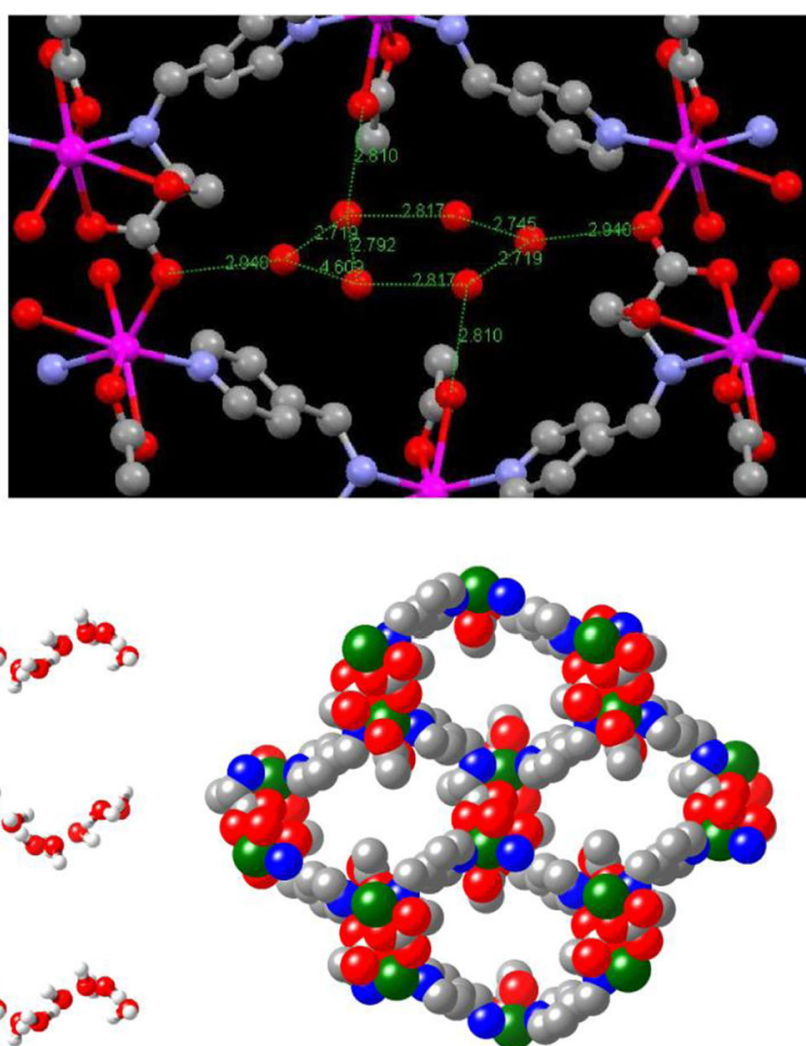

(d)

Figure 3. (a) Ball and stick representation of the SerCdOAc MOF showing arrangement of the water molecules within the tetragonal polar voids viewed from the crystallographic $a$ axis. (b) Hydrogen bonding interactions between the water molecules as well as the framework backbone (acetate and carboxylate moieties) depicted with the bonding distances. (c) Helical hydrogen bonded assembly of the solvent water molecules along the rectangular pore. (d) Space filling model of the SerCdOAc MOF featuring polar tetragonal voids. Water molecules have been removed for clarity. Colour codes: Cd (dark green), N (blue), O (red), C (gray) and $\mathrm{H}$ (white).

methanol molecule in the asymmetric unit (figure 5a). The $\mathrm{Zn}(\mathrm{II})$ centre adopts a slightly distorted square bipyramidal geometry (figure 4), chelated by monodentate carboxylate $[(\mathrm{Zn} 1-\mathrm{O} 1 ; 2.018(1) \AA)$, one amino functionality $[(\mathrm{Zn} 1-\mathrm{N} 2 ; 2.212(3) \AA)]$ and one pyridyl functionality $[(\mathrm{Zn} 1-\mathrm{N} 1 ; 2.208(3) \AA)]$ of the Ser linker coordinate to the $\mathrm{Zn}(\mathrm{II})$. Interestingly, the hydroxymethyl $\left(-\mathrm{CH}_{2} \mathrm{OH}\right)$ group of the Ser linker is free for both the linkers. All adjacent $\mathrm{Zn}(\mathrm{II})$ nodes are connected by the pyridyl, amino and carboxylate functionalities (figure 6a). The pyridyl rings constitute the triangular pore wall of the framework (figure 6b), which

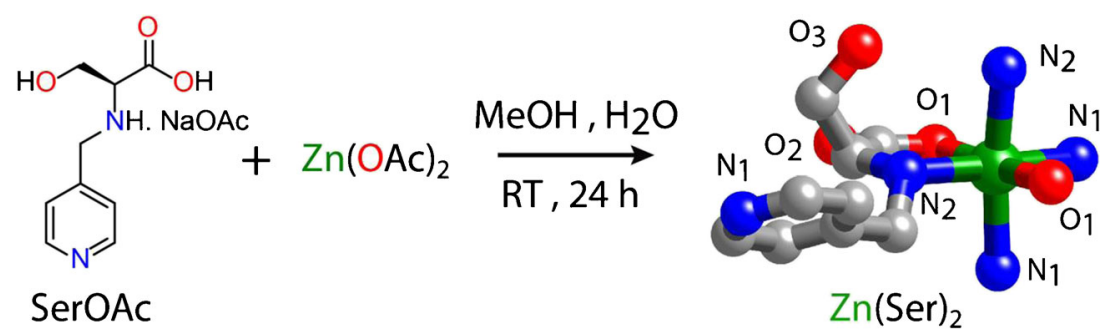

Figure 4. Schematic representation of the linker SerOAc which react with $\mathrm{Zn}(\mathrm{OAc})_{2}$ to produce corresponding $\mathrm{Zn}(\mathrm{Ser})_{2} \mathrm{MOF}$ architecture. Color codes: Zn (dark green), $\mathrm{N}$ (blue), O (red), C (gray) and H (white). 


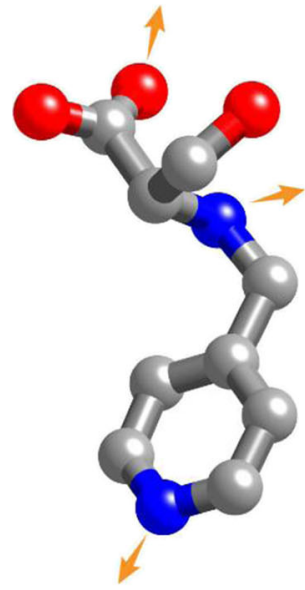

(a)

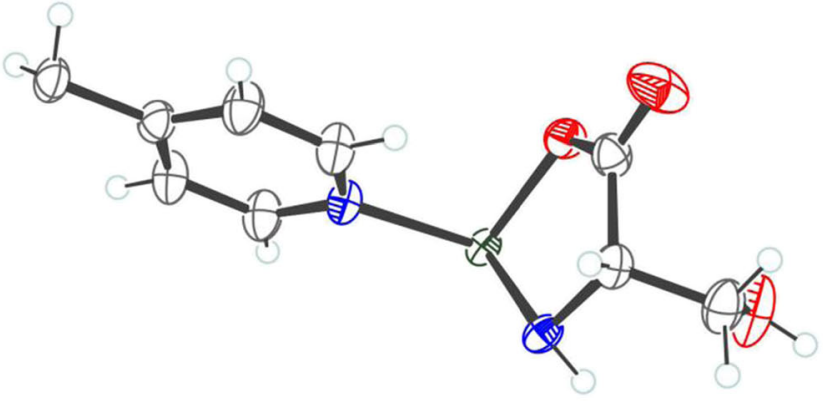

(b)

Figure 5. (a) Ligand (Ser) coordination mode in the $\mathrm{Zn}(\mathrm{Ser})_{2} \mathrm{MOF}$. (b) ORTEP diagram of $\mathrm{Zn}(\mathrm{Ser})_{2} \mathrm{MOF}$ with all the atoms at $50 \%$ probability level.

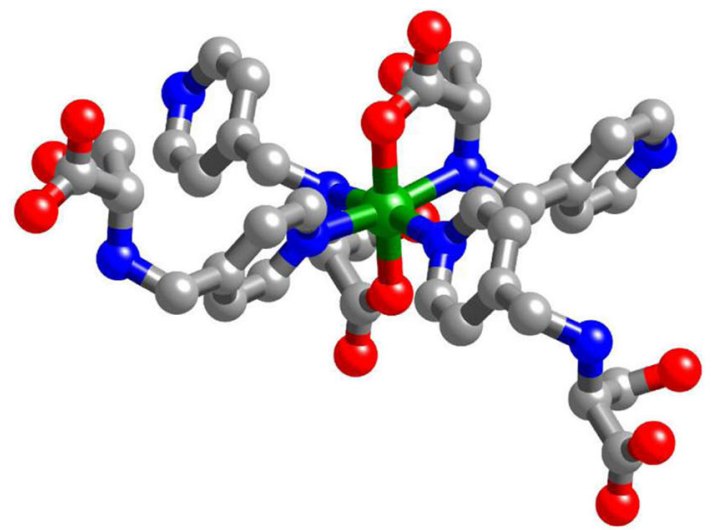

(a)

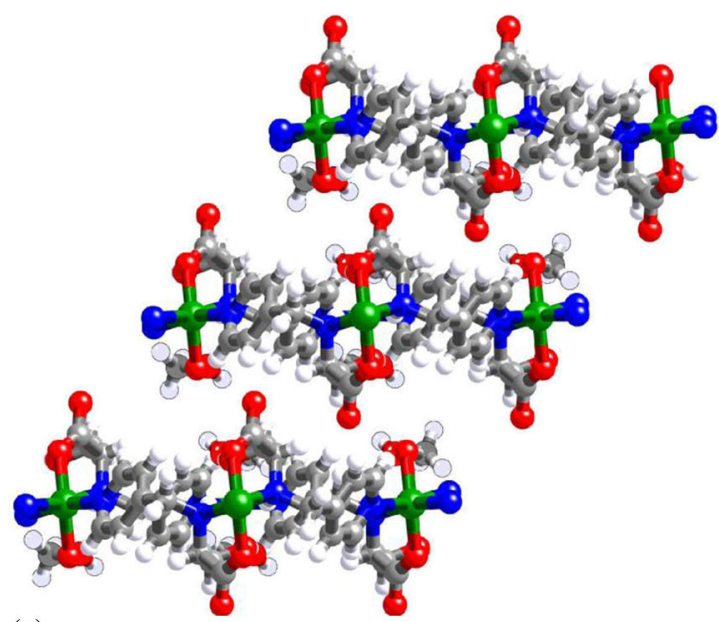

(c)

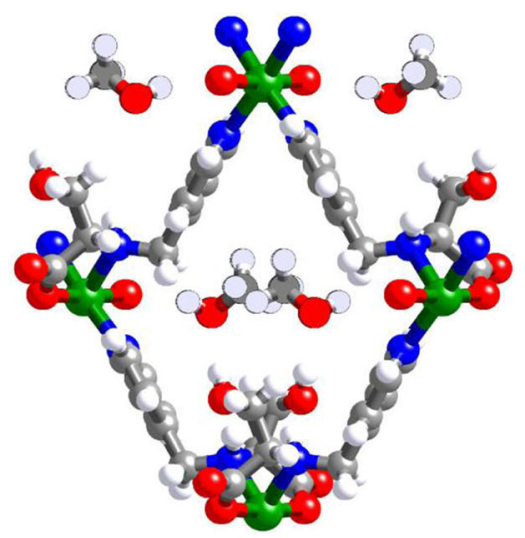

(b)

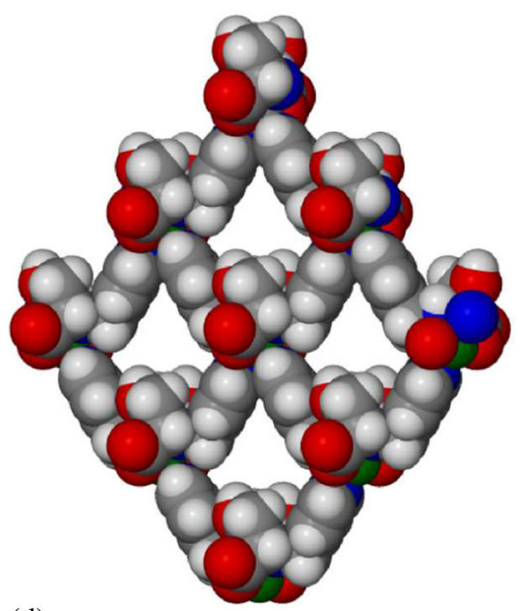

(d)

Figure 6. (a) Arrangement of Ser ligands and their coordination modes across the $\mathrm{Zn}$ centre in $\mathrm{Zn}(\mathrm{Ser})_{2}$. (b) Representation of a single pore of $\mathrm{Zn}(\mathrm{Ser})_{2}$ with a view of the solvent methanol molecules from the crystallographic $c$ axis. (c) 2D layer or sheet like architecture in $\mathrm{Zn}(\mathrm{Ser})_{2}$ as viewed from crystallographic $b$ axis. (d) Spacefill model representation of the $\mathrm{Zn}(\mathrm{Ser})_{2}$ from crystallographic $c$ axis showing the triangular voids. Methanol molecules have been removed for clarity. Color codes: Zn (dark green), N (blue), O (red), C (gray) and $\mathrm{H}$ (white). 
is hydrophobic in nature. The open channels along crystallographic $c$-axis are filled with solvent methanol molecules. The methanol molecules are strongly hydrogen bonded by nearby oxygen atoms of the free hydroxymethyl $\left(-\mathrm{CH}_{2} \mathrm{OH}\right)$ group of the Ser linker $[(\mathrm{O} 3 \cdots \mathrm{O} 4$; $2.710(3) \AA$ and O4 ‥ H3; 1.900(3) ^)] (figure 3). These channels have a cylindrical cross sectional area of $7.5 \times$ $5.5 \AA$. The $2 \mathrm{D}$ layers are arranged in a sheet like fashion with a distance of ca. $6 \AA$ in between the layers (figure 6c).

The structural comparison of the two MOFs, viz., SerCdOAc and $\mathrm{Zn}(\mathrm{Ser})_{2}$, shows that the former has a 3D architecture, while 2D sheet like structure prevail in the later case. Although in both the MOFs, the central $\mathrm{Cd}$ atom adopts hexacoordinated slightly distorted square bipyramidal geometry, the SerCdOAc consists of one Ser ligand utilizing six coordination modes (figure 2a) and a bidentate acetate anion, while the $\mathrm{Zn}(\mathrm{Ser})_{2}$ contains two Ser linker having three coordination mode (figure 5a). The $\mathrm{Cd}$ atom is oxygen rich in SerCdOAc and nitrogen rich in $\mathrm{Zn}(\mathrm{Ser})_{2}$. The hydroxymethyl groups are coordinated with $\mathrm{Cd}(\mathrm{II})$ in case of the SerCdOAc, while it is free and accessible for post synthetic modification in the $\mathrm{Zn}(\mathrm{Ser})_{2}$. The SerCdOAc structure adopts tetragonal pore (figure 3d), while in case of $\mathrm{Zn}(\mathrm{Ser})_{2}$ the pore becomes trigonal with reduced dimensions (figure 6d). Moreover, the SerCdOAc prefers water molecules as a crystallizing solvent to fill the empty pore, while methanol molecules fit the role in $\mathrm{Zn}(\mathrm{Ser})_{2}$. These differences led to the structural diversity of the MOFs, which will help to design further MOFs with tunable structures and properties.

\subsection{X-ray powder diffraction and thermogravimetric (TGA) analysis}

Confirmation of the phase purity of the bulk material was carried out on both using powder x-ray diffraction (PXRD) experiments. Experimental and simulated PXRD patterns for SerCdOAc and $\mathrm{Zn}(\mathrm{Ser})_{2}$ are shown in figures $7 \mathrm{a}$ and $7 \mathrm{c}$, respectively. All the major peaks of experimental PXRD match quite well with the simulated one, indicating reasonable crystalline phase purity in the bulk scale material.
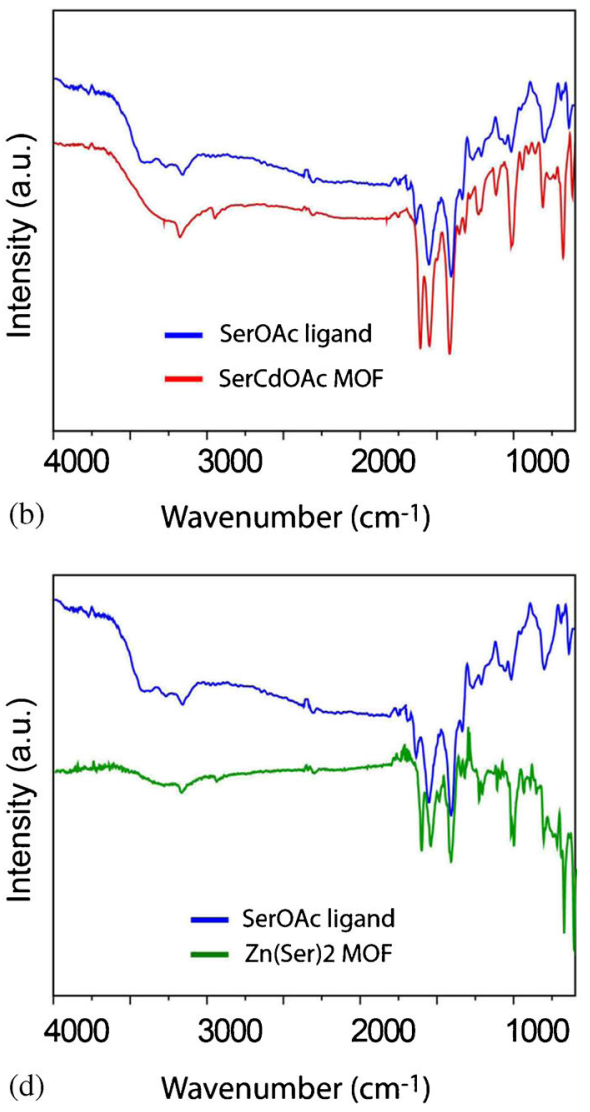

(d)

Wavenumber $\left(\mathrm{cm}^{-1}\right)$

Figure 7. (a) PXRD pattern of the SerCdOAc compared with the simulated pattern. (b) FT-IR spectra of the SerCdOAc compared with the ligand. (c) PXRD pattern of the $\mathrm{Zn}(\mathrm{Ser})_{2}$ compared with the simulated pattern. (d) FT-IR spectra of the $\mathrm{Zn}(\mathrm{Ser})_{2}$ compared with the ligand. 

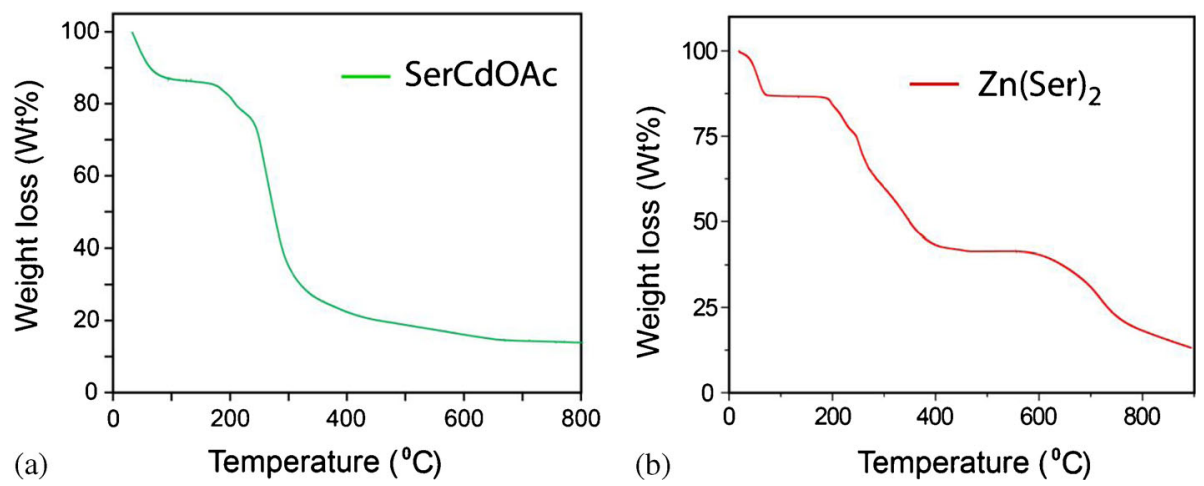

Figure 8. (a) TGA profile of the SerCdOAc under nitrogen environment in between 20-900 ${ }^{\circ}$. (b) $\mathrm{TGA}$ profile of the $\mathrm{Zn}(\mathrm{Ser})_{2}$ under nitrogen environment in between $20-800^{\circ} \mathrm{C}$.

Thermo-gravimetric analysis (TGA) performed on as-synthesized MOFs revealed that SerCdOAc has high thermal stability for all data regarding guest mobility and thermochemical stability. The TGA trace for SerCdOAc (figure 8a) showed a gradual weight-loss step of $12.5 \%$ [ $3 \mathrm{H}_{2} \mathrm{O}$; calcd. $12.8 \%$ ] $\left(20-120^{\circ} \mathrm{C}\right)$, corresponding to the escape of all $\mathrm{H}_{2} \mathrm{O}$ molecules trapped in the pores followed by a plateau $\left(120-205^{\circ} \mathrm{C}\right)$ indicating its high thermal stability in absence of guest molecules (figure $8 \mathrm{a})$. Further weightloss ( 55\%) indicates the decomposition of the framework. $\mathrm{Zn}(\mathrm{Ser})_{2}$ also exhibit high guest mobility and thermochemical stability, as evident from its TGA profile. The TGA trace for $\mathrm{Zn}(\mathrm{Ser})_{2}$ showed a gradual weightloss step of $12.1 \%$ [2 $\mathrm{MeOH}$; calcd. $12.3 \%$ ] $\left(20-70^{\circ} \mathrm{C}\right)$, corresponding to the escape of all $\mathrm{H}_{2} \mathrm{O}$ molecules trapped in the pores followed by a plateau $\left(70-195^{\circ} \mathrm{C}\right)$ indicating its high thermal stability in absence of guest molecules (figure $8 b)$. Further weightloss $(\sim 45 \%)$ indicates the decomposition of the framework entity.

Table 1. Crystal data and structure refinement for SerCdOAc.

\begin{tabular}{|c|c|}
\hline Identification code & SerCdOAc \\
\hline Empirical formula & $\mathrm{C}_{11} \mathrm{H}_{20} \mathrm{CdN}_{2} \mathrm{O}_{8}$ \\
\hline Formula weight & 420.70 \\
\hline Temperature/K & $100(2)$ \\
\hline Crystal system & orthorhombic \\
\hline Space group & $P 2_{1} 2_{1} 2_{1}$ \\
\hline $\mathbf{a} / \AA ̊$ & $6.1983(5)$ \\
\hline b/Å & $15.0070(15)$ \\
\hline c/Å & $16.5317(16)$ \\
\hline$\alpha /{ }^{\circ}$ & 90.00 \\
\hline$\beta /^{\circ}$ & 90.00 \\
\hline$\gamma /{ }^{\circ}$ & 90.00 \\
\hline Volume $/ \AA^{3}$ & $1537.8(2)$ \\
\hline $\mathbf{Z}$ & 4 \\
\hline$\rho_{\text {calc }} \mathbf{m g} / \mathbf{m m}^{3}$ & 1.817 \\
\hline $\mathbf{m} / \mathbf{m m}^{1}$ & 1.461 \\
\hline $\mathbf{F}(\mathbf{0 0 0})$ & 848 \\
\hline Crystal size $/ \mathrm{mm}^{3}$ & $0.50 \times 0.20 \times 0.20$ \\
\hline Theta range for data collection & 5.96 to $58.18^{\circ}$ \\
\hline Index ranges & $-8 \leq \mathrm{h} \leq 3,-19 \leq \mathrm{k} \leq 16,-19 \leq 1 \leq 21$ \\
\hline Reflections collected & $43 \overline{46}$ \\
\hline Independent reflections & $3041[\mathrm{R}(\mathrm{int})=0.0706]$ \\
\hline Data/restraints/parameters & $3041 / 2 / 212$ \\
\hline Goodness-of-fit on $F^{2}$ & 1.036 \\
\hline Final $\mathbf{R}$ indexes $[\mathbf{I}>2 \sigma(\mathbf{I})]$ & $\mathrm{R}_{1}=0.0442, w \mathrm{R}_{2}=0.1029$ \\
\hline Final $R$ indexes [all data] & $\mathrm{R}_{1}=0.0499, w \mathrm{R}_{2}=0.1142$ \\
\hline Largest diff. peak/hole / e $\AA^{-3}$ & $1.077 /-0.650$ \\
\hline
\end{tabular}


Table 2. Crystal data and structure refinement for $\mathrm{Zn}(\mathrm{Ser}) 2$.

\begin{tabular}{|c|c|}
\hline Identification code & $\mathrm{Zn}(\mathrm{Ser}) 2$ \\
\hline Empirical formula & $\mathrm{C}_{20} \mathrm{H}_{30} \mathrm{~N}_{4} \mathrm{O}_{8} \mathrm{Zn}$ \\
\hline Formula weight & 519.87 \\
\hline Temperature/K & 293(2) \\
\hline Crystal system & monoclinic \\
\hline Space group & $C 2$ \\
\hline $\mathbf{a} / \AA$ & $13.3648(6)$ \\
\hline $\mathbf{b} / \mathbf{A}$ & $13.2781(3)$ \\
\hline $\mathbf{c} / \mathbf{A}$ & $8.7485(3)$ \\
\hline$\alpha / /^{\circ}$ & 90.00 \\
\hline$\beta /{ }^{\circ}$ & $124.168(6)$ \\
\hline$\gamma /{ }^{\circ}$ & 90.00 \\
\hline Volume $/ \AA^{3}$ & $1284.53(8)$ \\
\hline $\mathbf{Z}$ & 2 \\
\hline$\rho_{\text {calc }} \mathrm{mg} / \mathrm{mm}^{3}$ & 1.344 \\
\hline $\mathbf{m} / \mathbf{m m}^{1}$ & 1.004 \\
\hline $\mathbf{F}(\mathbf{0 0 0})$ & 544 \\
\hline Crystal size $/ \mathrm{mm}^{3}$ & $0.5 \times 0.2 \times 0.2$ \\
\hline Theta range for data collection & 6.14 to $58.44^{\circ}$ \\
\hline Index ranges & $-17 \leq \mathrm{h} \leq 17,-17 \leq \mathrm{k} \leq 16,-11 \leq \mathrm{l} \leq 11$ \\
\hline Reflections collected & 2939 \\
\hline Independent reflections & $2202[\mathrm{R}(\mathrm{int})=0.0176]$ \\
\hline Data/restraints/parameters & $2202 / 1 / 153$ \\
\hline Goodness-of-fit on $\mathrm{F}^{2}$ & 1.064 \\
\hline Final $\mathbf{R}$ indexes $[I>2 \sigma(I)$ & $\mathrm{R}_{1}=0.0275, \mathrm{wR}_{2}=0.0613$ \\
\hline Final $\mathbf{R}$ indexes [all data] & $\mathrm{R}_{1}=0.0287, \mathrm{wR}_{2}=0.0623$ \\
\hline Largest diff. peak/hole / e $\AA^{-3}$ & $0.269 /-0.204$ \\
\hline
\end{tabular}

\section{Conclusion}

Research on amino acid based MOFs are still in its early stage and sufficient understanding is needed on amino acid based MOFs for their structure and subsequent property change with respect to coordinate covalent bonding with metal ions. In this manuscript, we have systematically explored structural diversity using $\mathrm{Cd}(\mathrm{II})$ and $\mathrm{Zn}$ (II) as metal node, keeping the linker entity same. This resulted in the generation of a 3D MOF, i.e., SerCdOAc, and a $2 \mathrm{D}$ MOF viz., $\mathrm{Zn}(\mathrm{Ser})_{2}$. In case of SerCdOAc one Ser ligand and one acetate anion bind to the $\mathrm{Cd}(\mathrm{II})$, while two Ser linker bind the $\mathrm{Zn}$ (II) in case of $\mathrm{Zn}(\mathrm{Ser})_{2}$. Both the MOFs feature hydrophilic pore surface, and encapsulate helical water chain in case of SerCdOAc and methanol molecules in between the 2D layers of the $\mathrm{Zn}(\mathrm{Ser})_{2}$. The rational synthesis of these MOFs open up new avenues towards realizing functionalized chiral MOFs with utility in industrially relevant chiral solvent sorption and separation.

\section{Acknowledgement}

T K acknowledges CSIR, New Delhi, India, for a SRF. R.B. acknowledges CSIR's XII Five Year Plan Project
(CSC0122) for funding. Financial assistance from the BRNS (2011/37C/44/BRNS) is acknowledged.

\section{References}

1. (a) Nakano $\mathrm{T}$ and Okamoto $\mathrm{Y} 2001$ Chem. Rev. 101 4013; (b) Watson J D and Crick F H C 1953 Nature 171 737; (c) Voet D, Voet J G and Pratt C W 1999 In Fundamentals of Biochemistry (New York: Wiley); (d) Schulz G E and Schirmer R H 1979 In Principles of Protein Structure (New York: Springer-Verlag); (e) Saenger W 1984 In Principles of Nucleic Acid Structure (New York: Springer-Verlag); (f) Moorthy J N, Mandal S and Venugopalan P 2012 Cryst. Growth Des. 12 2942; (g) Moorthy J N, Mandal S, Mukhopadhyay A and Samanta S 2013 J. Am. Chem. Soc. 1356872

2. (a) Mo K, Yang Y and Cui Y 2014 J. Am. Chem. Soc. 136 1746; (b) Cho S -H, Ma B, Nguyen S T, Hupp J T and Schmitt T E A 2006 Chem. Commun. 2563; (c) Ma L Q, Abney C and Lin W B 2009 Chem. Soc. Rev. 38 1248; (d) Wang C, Zheng M and Lin W 2011 J. Phys. Chem. Lett. 21701

3. (a) Dybtsev D N, Nuzhdin A L, Chun H, Bryliakov K P, Talsi E P, Fedin V P and Kim K 2006 Angew. Chem. 118 930; (b) Xiang S -C, Zhang Z, Zhao C -G, Hong K, Zhao X, Ding D -R, Xie M -H, Wu C -D, Das M C, Gill R, Thomas K M and Chen B 2010 Nat. Commun. 2 204; (c) Padmanaban M, Müller P, Lieder C, Gedrich K, Grünker R, Bon V, Senkovska I, Baumgärtner S, Opelt 
S, Paasch S, Brunner E, Glorius F, Klemm E and Kaskel S 2011 Chem. Commun. 47 12089; (d) Wang W, Dong X, Nan J, Jin W, Hu Z, Chen Y and Jiang J 2012 Chem. Commun. 487022

4. (a) Pana'kova D, Werdich A A and MacRae C A 2010 Nature 466 874; (b) Burykin A and Warshel A 2003 Biophys J. Dec. 853696

5. (a) Furukawa H, Gándara F, Zhang Y, Jiang J, Queen W L, Hudson M R and Yaghi O M 2014 J. Am. Chem. Soc. 136 4369; (b) Zhao X, Xiao B, Fletcher J A, Thomas K M, Bradshaw D and Rosseinsky M J 2004 Science 306 1012; (c) Ferey G, Mellot-Draznieks C, Serre C, Millange F, Dutour J, Surble S and Margiolaki I 2005 Science 309 2040; (d) Chandler B D, Enright G D, Udachin K A, Pawsey S, Ripmeester J A, Cramb D T and Shimizu G K H 2008 Nat. Mater. 7 229; (e) Chae H K, Siberio-Perez D Y, Kim J, Go Y, Eddaoudi M, Matzger A J, O'Keeffe M and Yaghi O M 2004 Nature 427 523; (f) Lin Z, Lü J, Hong M and Cao R 2014 Chem. Soc. Rev. $\mathbf{4 3} 5867$

6. (a) Lee J Y, Farha O K, Roberts J, Scheidt K A, Nguyen S T and Hupp J T 2009 Chem. Soc. Rev. 38 1450; (b) Seo J S, Whang D, Lee H, Jun S I, Oh J, Jeon Y J and Kim K 2000 Nature 404 982; (c) Zou R -Q, Sakurai $\mathrm{H}$ and Xu Q 2006 Angew. Chem. Int. Ed. 452542

7. (a) Kurmoo M 2009 Chem. Soc. Rev. 38 1353; (b) Tamaki H, Zhong Z J, Matsumoto N, Kida S, Koikawa M, Achiwa N, Hashimoto $\mathrm{Y}$ and Okawa H 1992 J. Am. Chem. Soc. 114 6974; (c) Ohba M and Okawa H 2000 Coord. Chem. Rev. 198 313; (d) Shiga T, Okawa H, Kitagawa S and Ohba M 2006 J. Am. Chem. Soc. 128 16426; (e) Zeng M -H, Wang B, Wang X -Y, Zhang W -X, Chen X -M and Gao S 2006 Inorg. Chem. 457069

8. (a) Kundu T, Sahoo S C and Banerjee R 2012 Chem. Commun. 48 4998; (b) T Panda, Kundu T and Banerjee R 2012 Chem. Commun. 48 5464; (c) Mallick A, Kundu T and Banerjee R 2012 Chem. Commun. 48 8829; (d) Bureekaew S, Horike S, Higuchi M, Mizuno M, Kawamura T, Tanaka D, Yanai N and Kitagawa S 2009 Nat. Mater. 8 831; (e) Hurd J A, Vaidhyanathan R, Thangadurai V, Ratcliffe C I, Moudra- kovski I M and Shimizu G K H 2009 Nat. Chem. 1 705; (f) Wiers B M, Foo M -L, Balsara N P and Long J R $2011 \mathrm{~J}$. Am. Chem. Soc. 133 14522; (g) Taylor J M, Mah R K, Moudrakovski I L, Ratcliffe C I, Vaidhyanathan R and Shimizu G K H 2010 J. Am. Chem. Soc. 132 14055; (h) Okawa H, Shigematsu A, Sadakiyo M, Miyagawa T, Yoneda K, Ohba M and Kitagawa H 2009 J. Am. Chem. Soc.131 13516; (i) Panda T, Kundu T and R Banerjee 2013 Chem. Commun. 49 6197; (j) Shigematsu A,
Yamada T and Kitagawa H $2011 \mathrm{~J}$. Am. Chem. Soc. 133 2034

9. (a) Vaidhyanathan R, Bradshaw D, Rebilly J-N, Barrio J P, Gould J A, Berry N G and Rosseinsky M J 2006 Angew. Chem. Int. Ed. 45 6495; (b) Bradshaw D, Claridge J B, Cussen E J, Prior T J and Rosseinsky M J 2005 Acc. Chem. Res. 38 273; (c) Rebilly J, Gardner P W, Darling G R, Bacsa J and Rosseinsky M J 2008 Inorg. Chem. 479390

10. (a) Ong T T, Kavuru P, Nguyen T, Cantwell R, Wojtas Łand Zaworotko M J 2011 J. Am. Chem. Soc. 133 9224; (b) Sasmal P K, Patra A K, Nethaji M and Chakravarty A R 2007 Inorg. Chem. 46 11113; (c) Tovar A T, Ramrez L R, Campero A, Romerosa A, Esparza R M and Hoz M J R 2004 J. Inorg. Biochem. 98 1045; (d) Zhang J -J, Sheng T -L, Hu S -M, Xia S -Q, Leibeling G, Meyer F, Fu Z -Y, Chen L, Fu R -B and Wu X -T 2004 Chem. Eur. J. 10 3963; (e) Kumar D K, Das A and P Dastidar 2007 Cryst. Eng. Comm. 9548

11. (a) Sahoo S C, Kundu T and Banerjee R 2011 J. Am. Chem. Soc. 133 17950; (b) Kundu T, Sahoo S C and Banerjee R 2012 Cryst. Growth and Des. 12 4633; (c) Kundu T, Sahoo S C and Banerjee R 2013 Cryst. Eng. Comm. 15 9634; (d) Kundu T, Sahoo S C and Banerjee R 2013 Chem. Commun. 495262

12. (a) Bruker (2005). APEX2. Version 5.053. Bruker AXS Inc., Madison,Wisconsin, USA; (b) Bruker 2004 SAINT-Plus (Version 7.03). Bruker AXS Inc., Madison, Wisconsin, USA; (c) Sheldrick, G M 2002 SADABS (Version 2.03) and TWINABS (Version 1.02). University of Göttingen, Germany; (d) Sheldrick, G M 1997 SHELXS '97 and SHELXL '97. University of Göttingen, Germany; (e) Spek A L 2005 PLATON: A Multipurpose Crystallographic Tool (The Netherlands: Utrecht University)

13. Wang M, Xie M, Wu C and Wang Y 2009 Chem. Commun. 2396

14. (a) Desiraju G R and Steiner T 1999 In The Weak Hydrogen Bond in Structural Chemistry and Biology (Oxford: Oxford University Press); (b) Kovacs A, Szabo A and Hargittai I 2002 Acc. Chem. Res. 35 887; (c) Bajpai A, Venugopalan P and Moorthy J N 2014 CrystEngComm DOI: 10.1039/C3CE42515K; (d) Vangala V R, Bhogala B R, Dey A, Desiraju G R, Broder C K, Smith P S, Mondal R, Howard J A K and Wilson C C $2003 \mathrm{~J}$. Am. Chem. Soc. 125 14495; (e) Bajpai A, Venugopalan P, Natarajan P and Moorthy J N 2012 J. Org. Chem. 77 7858; (f) Murugavel R, Choudhury A, Walawalkar M G, Pothiraja R and Rao C N R 2008 Chem. Rev. 108 3549; (g) Murugavel R, Kumar P, Walawalkar M G and Mathialagan R 2007 Inorg. Chem. 466828 